\title{
Detection of tomato anthracnose caused by Colletotrichum truncatum in India
}

\author{
T. J. Saini ${ }^{1,2}$ - S. G. Gupta ${ }^{3}$ - R. Anandalakshmi ${ }^{1}$
}

Received: 21 February 2017 / Accepted: 25 August 2017 / Published online: 2 September 2017

(C) Australasian Plant Pathology Society Inc. 2017

\begin{abstract}
Tomato fruits with typical anthracnose symptoms of small, sunken, dark brown lesions were observed in the farmers fields in Jalna, Maharashtra, India. Based on morphological and molecular characterization, the fungus was identified as Colletotrichum truncatum, which is reported for the first time causing anthracnose on tomato in India.
\end{abstract}

\section{Keywords Solanum lycopersicum}

Tomato, Solanum lycopersicum, is one of the most important vegetable/fruit crops of India. Anthracnose (fruit rot) of tomato caused by Colletotrichum species is an important disease worldwide, resulting in post-harvest fruit decay, which severely affects marketability of the fruits. In August 2016, tomato fruits $(5 \%)$ showing typical anthracnose symptoms of small, sunken, dark brown lesions were observed in two different fields in Jalna, Maharashtra (Fig. 1). Five tomato fruits showing typical anthracnose symptoms were collected and transported to a laboratory at Mahyco research centre, Jalna for study.

Tomato fruits showing anthracnose symptoms were surface sterilized with $1 \% \mathrm{NaOCl}$ for $2 \mathrm{~min}$ and then rinsed twice with sterile distilled water. Surface sterilized sunken necrotic tissue

T. J. Saini

teju.saini@gmail.com

1 Mahyco Research Centre, Dawalwadi, Jalna, Maharashtra 431203, India

2 Department of Biotechnology, Government Institute of Science, Dr. Babasaheb Ambedkar Marathwada University, Aurangabad, Maharashtra 431004, India

3 Government Institute of Forensic Science, Nipatniranjan nagar, Aurangabad, Maharashtra 431004, India of tomato was examined under a microscope. Twenty $\mu$ of sterile distilled water was dispensed onto each visible acervulus. Conidia were pipetted out and their presence was checked under a microscope. Serial dilutions of conidial suspension were made by adding sterile distilled water until a spore concentration of 1 or 2 spores per $10 \mu \mathrm{l}$ was achieved. Ten $\mu \mathrm{l}$ of conidial suspension was pipetted into each of six sectors on the surface of potato dextrose agar (PDA) containing $50 \mathrm{mg} / 1$ streptomycin sulphate in 9-cm-diameter petri dishes and allowed to dry in laminar air flow cabinet for $5 \mathrm{~min}$. Plates were then incubated at $28{ }^{\circ} \mathrm{C}$, with $16 / 8 \mathrm{~h}$ light/dark cycle, respectively, for 3 to 4 days and a pure culture of the Colletotrichum isolate was obtained by sub-culturing on fresh PDA plates. Initial identification of all three pure cultures of the Colletotrichum isolates was done on the basis of morphological characteristics of conidia. Colonies of the Colletotrichum isolate were grey colored and had a mean growth rate on PDA at $28{ }^{\circ} \mathrm{C}$ and a $16 \mathrm{~h} \mathrm{light} / 8 \mathrm{~h}$ dark

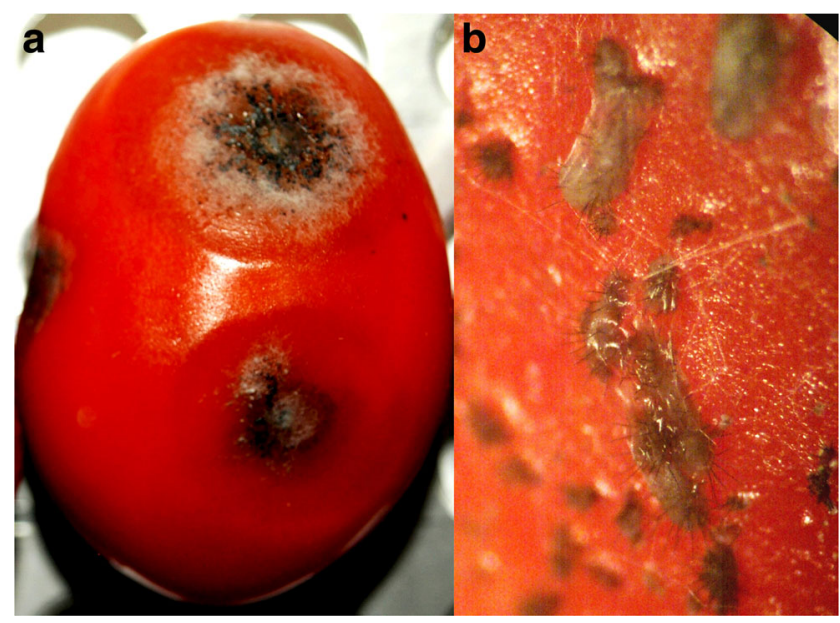

Fig. 1 a anthracnose symptoms on tomato fruit; $\mathbf{b}$ acervuli 
Fig. 2 Colletotrichum truncatum on PDA, ten days post

inoculation, (a) from above; (b) from below

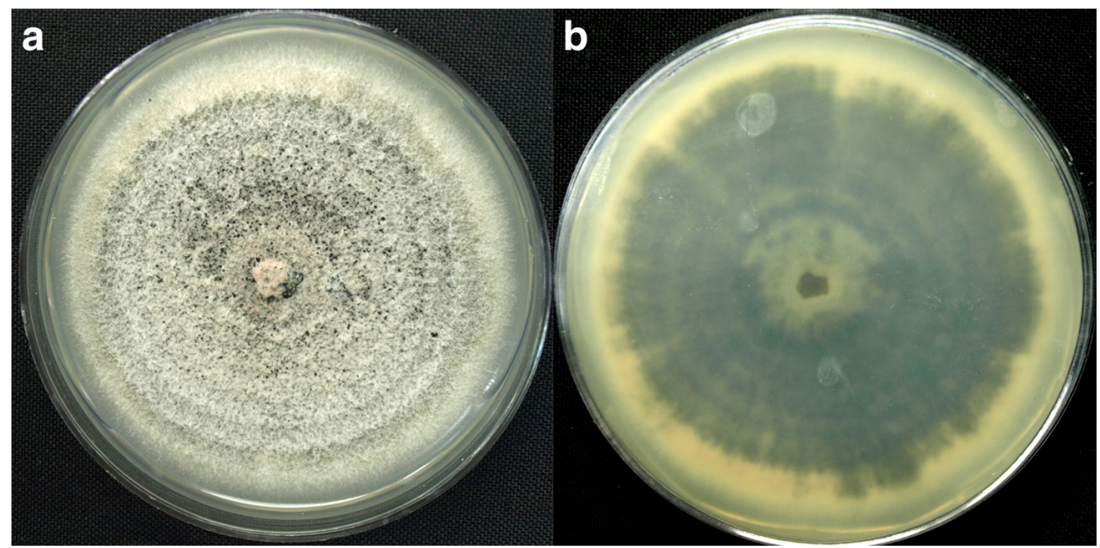

photoperiod of $8 \mathrm{~mm} /$ day. Acervuli were scattered across the colonies and contained dark grey conidial masses and dark setae (Fig. 2). Conidia were aseptate, hyaline, thin walled, falcate and 24.0-29.4 $\times 3.9-4.9 \mu \mathrm{m}(\bar{x}=$ $26.4 \pm 1.3 \times 4.5 \pm 0.3 \mu \mathrm{m}, n=20)$. The morphological characteristics of this fungal isolate matched with the description of Colletotrichum truncatum (Damm et al. 2009).

PCR amplification of ITS rDNA, using the universal primer pair ITS 4/5 (ITS region of the nuclear ITS1-5.8S - ITS2 rDNA; White et al. 1990) and partial $\beta$-tubulin gene using $\mathrm{Bt} 2 \mathrm{a} / \mathrm{b}$ primers (Glass and Donaldson 1995) was conducted for molecular characterization of the Colletotrichum isolate. Blast searches in the NCBI database revealed that ITS and $\beta$ tubulin gene sequences (Accession Nos KY399773 and KY399774, respectively) had $99 \%$ and $100 \%$ similarity to
C. truncatum (KX197395 and KP823848, respectively). Based on phylogenetic analyses and morphological characteristics, the Colletotrichum isolate obtained from infected tomato fruit was confirmed as $C$. truncatum. A pure culture of C. truncatum has been deposited in the National Fungal Culture Collection of India (NFCCI), Agharkar Research Institute, Pune, India (Accession No.4127).

To confirm pathogenicity of $C$. truncatum isolate 4127 , ten fruits of each tomato cv. Arka saurabh and chilli (Capsicum annum cv. Phule jyoti) were obtained from plants raised in a green house. Fruits were first washed with sterile distilled water and then surface sterilised with $70 \%$ ethanol for $30 \mathrm{~s}$. Tomato and chilli fruits were then pin pricked with a sterile syringe. Five fruits of each tomato and chilli were inoculated on pin pricks with $10 \mu \mathrm{l}$ of $C$. truncatum isolate 4127 spores
Fig. 3 a development of anthracnose symptoms on tomato fruit following artificial inoculation of Colletotrichum truncatum; b acervuli; c conidiophores with conidia; $\mathbf{d}$ setae. Bars: $c-d=50 \mu \mathrm{m}$

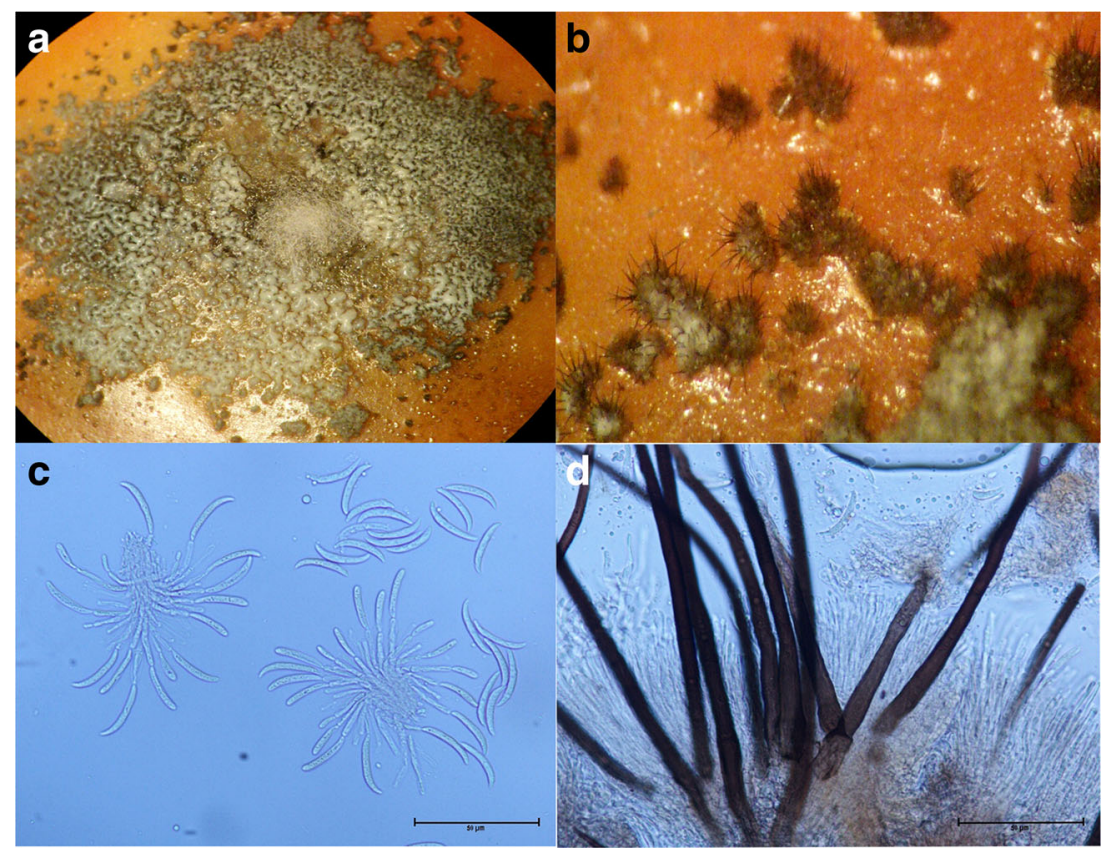


Fig. 4 a development of anthracnose symptoms on chilli fruit following artificial inoculation of Colletotrichum truncatum; b acervuli; c setae. Bar: $\mathrm{c}=50 \mu \mathrm{m}$

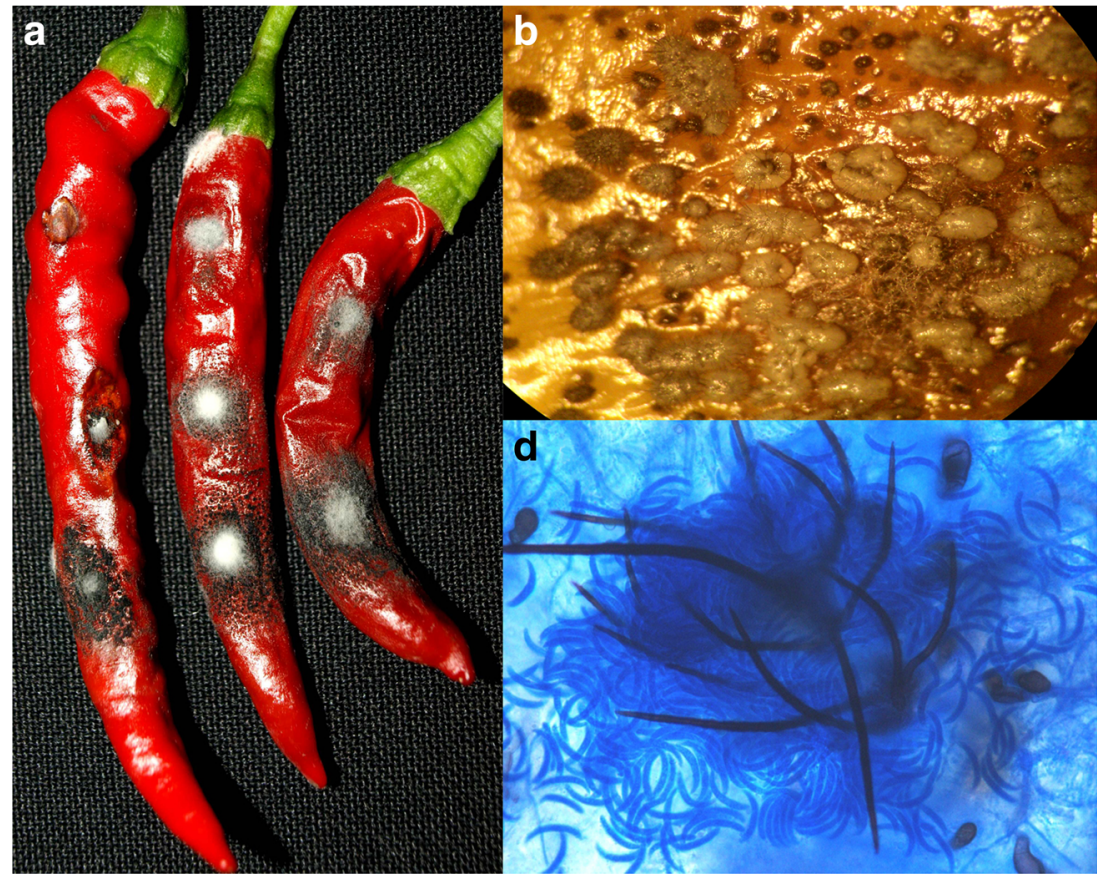

(c. $10^{5}$ conidia $/ \mathrm{ml}$ ), obtained from the PDA culture plate while 5 fruits were inoculated with sterile water and used as controls. Inoculated tomato and chilli fruits were incubated in a chamber at $28{ }^{\circ} \mathrm{C}$ in dark with $90 \%$ humidity. After seven days, typical anthracnose symptoms developed on inoculated tomato (Fig. 3) and chilli fruits (Fig. 4). Pathogenicity experiment was repeated three times. Conidia were re-isolated from these diseased inoculated tomato and chilli fruits and observed under a microscope. Colony morphology, conidial measurements and sequences were identical to the original inoculated C. truncatum isolate 4127, thereby fulfilling Koch's postulates.

C. truncatum as a causal agent of chilli anthracnose has been reported in India (Chethana et al. 2015) and is reported to cause tomato anthracnose in China (Diao et al. 2014). To our knowledge, this is the first report of tomato anthracnose caused by $C$. truncatum in India.

\section{References}

Chethana CS, Chowdappa P, Pavani KV (2015) Colletotrichum truncatum and $C$. fructicola causing anthracnose on chilli in Karnataka state of India. Indian Phytopathol 68:270-278

Damm U, Woudenberg JHC, Cannon PF, Crous PW (2009) Colletotrichum species with curved conidia from herbaceous hosts. Fungal Divers 39:45-87

Diao YZ, Zhang C, Lin D, Liu XL (2014) First report of Colletotrichum truncatum causing anthracnose of tomato in China. Plant Dis 98: 687. https://doi.org/10.1094/PDIS-05-13-0491-PDN

Glass NL, Donaldson GC (1995) Development of primer sets designed for use with the PCR to amplify conserved genes from filamentous ascomycetes. Appl Environ Microbiol 61:1323-1330

White TJ, Bruns T, Lee S, Taylor J (1990) Amplification and direct sequencing of fungal ribosomal RNA genes for phylogenetics. In: Innis MA, Gelfand DH, Sninsky JJ, White TJ (eds) PCR Protocols: A Guide to Methods and Applications. Academic Press, New York, pp 315-322 